\title{
Epistemological Limits to Scientific Prediction: The Problem of Uncertainty
}

\author{
Amanda Guillan \\ Department of Humanities, University of A Coruña, A Coruña, Spain \\ Email: a.guillan@udc.es
}

Received 28 August 2014; revised 26 September 2014; accepted 10 October 2014

Copyright (C) 2014 by author and Scientific Research Publishing Inc.

This work is licensed under the Creative Commons Attribution International License (CC BY). http://creativecommons.org/licenses/by/4.0/

(c) (i) Open Access

\begin{abstract}
A key issue regarding the reliability of scientific prediction is uncertainty, which also affects its possibility as scientific knowledge. Thus, uncertainty is directly related to the epistemological limits of prediction in science. Within this context, this paper considers the obstacles to scientific predictions that are related to uncertainty. The analysis is made according to the twofold character of the limits of science, which is characterized in terms of the "barriers" and the "confines." In addition, the study takes into account the presence of internal and external factors related to the epistemological limits of science. Following these lines of research, the analysis is focused on two steps. First, there is a characterization of the coordinates of Nicholas Rescher's approach, which is particularly important regarding the epistemological limits to scientific prediction. Second, there is a study of uncertainty as an epistemological obstacle to predictability. Thereafter, the consequences for the future are pointed out.
\end{abstract}

\section{Keywords}

Rescher, Scientific Prediction, Uncertainty, Epistemological Limits, Obstacles

\section{Introduction: The Twofold Problem of the Limits of Science}

Initially, two different aspects of the problem of the limits of science can be distinguished. This twofold possibility also involves different epistemological analyses regarding scientific prediction. Firstly, there is the problem of the possibility of "barriers" (Schranken) or boundaries that might separate what is scientific from what is non-scientific. Secondly, there is the issue of scientific "confines" (Grenzen), i.e., the question of the possible ceiling of scientific knowledge that can be reached by scientific activity (cf. Radnitzky, 1978).

Both aspects- "barriers" and "confines"-are involved when the problem of the limits of prediction is considered. They should be taken into account, because they deal with two sides of the epistemological problem of prediction. Moreover, they are commonly present in the development of scientific predictions. On the one hand, 
the "barriers" of the scientific prediction are needed insofar as we need to know when science ends and where a non-science starts ${ }^{1}$. On the other, we need to reflect when the possibility of scientific prediction ends (and, therefore, its reliability), which requires considering the terminal limits that scientific knowledge can reach.

These two dimensions concerning scientific limits to prediction should be considered in epistemological terms. Thus, the "barriers" that shape scientific prediction and separate it from non-scientific prediction can be examined. This is a matter that not only affects the social sciences, but also the natural sciences (as it can be seen in the case of climate change) as well as the sciences of the artificial ${ }^{2}$. In addition, there is the problem of what "confines" of predictions might be (i.e., where the possibility of scientific prediction ends). This issue has repercussions on the scope of reliable scientific prediction. Consequently, it clearly has to do with the obstacles that make predictive activity difficult.

In this regard, Nicholas Rescher has considered the limits of scientific prediction from the two settled viewpoints: "barriers" and "confines". But his attention is above all on the problem of "confines". He does so from some clear coordinates: he proposes an approach where the internal elements have primacy over the external factors of that human activity. Thus, he points out a series of epistemological and ontological factors that act as obstacles to scientific prediction. In that respect, in his judgment, uncertainty, chance and chaos are noticeable (cf. Rescher, 1998: ch. 8, pp. 133-156). But this also requires awareness of internal and external features, because science is a human activity with an epistemological content as well as an undertaking in a social milieu.

Within this thematic framework, where the twofold character of the limits of science-the barriers and the confines-is emphasized, and the presence of internal and external factors is recognized, this paper seeks to shed light on the obstacles to scientific predictions that are related to uncertainty. In order to develop this task, two steps are followed within this theoretical context: firstly, the attention goes to the general coordinates of Rescher's approach to epistemological limits to scientific prediction; and secondly, the focus moves to uncertainty as an epistemological obstacle to predictability.

\section{Nicholas Rescher's Approach to Epistemological Limits to Scientific Prediction}

In a specific book on The Limits of Science ${ }^{3}$, Rescher pays special attention to the epistemological limits. In addition, he is interested in the limits to scientific prediction. His philosophical conception, which he labels as "pragmatic idealism", can be found in the three volumes that he has devoted to a "system of pragmatic idealism" (cf. Rescher 1992; 1993; and 1994). In fact, he is a pragmatist philosopher, insofar as he highlights the realm of human activity and the primacy of practice. In addition, he is as a Kantian thinker on human knowledge. Thus, he insists that human knowledge is modulated by our mental categories and concepts. Consequently, the role of ideas has primacy in his approach, to the extent that he considers them as crucial for the characterization of reality.

This proposal discusses the issue of limits, both to science, in general, and to scientific prediction, in particular. In his perspective, science is the product of the interaction between the human being and nature, so that it is an activity subject to limits (cf. Rescher, 1990). On the one hand, Rescher considers the limits to research as a human undertaking: science is developed by the human being with bounded capabilities; and, on the other, he takes into account the limits that are due to the reality of phenomena, which can be complex (cf. Gonzalez, 2010: pp. 253-281; especially, pp. 274-277).

When the focus of attention moves from the general limits of science to the limits of scientific prediction, then we have two main aspects: 1) limits that are related with agents (i.e., the epistemological obstacles); and 2) limits due to the complexity of the real world (i.e., the ontological limits). Both are relevant when we want to predict the possible future. Even more, it is necessary to highlight that Rescher considers that predicting the future is more difficult than explaining facts that already happened (cf. Rescher, 1998: p. 166). This is so because prediction is about phenomena that have not yet occurred, and the future has, at least in principle, a number of possibilities.

On the one hand, Rescher considers that prediction and explanation are asymmetric in their logical relations in

\footnotetext{
${ }^{1}$ The topic of the use of prediction as a scientific test is related to this issue. For Rescher, successful prediction and control are the best evidence we have about our scientific understanding of the world. But predictive success is not a test in a demonstrative sense, since there are areas where predictive success is possible (for example, regarding acupuncture or hypnosis) without scientific understanding. This leads him to insist on the role of control, because he thinks that, in order to have control of phenomena, we need both predictive success and scientific understanding of the phenomena at issue. Rescher, N., Personal communication, 17.6.2014.

${ }^{2}$ On the problem of prediction in the sciences of the artificial, cf. Gonzalez (2008), pp.165-186.

${ }^{3}$ This book has two different versions. The original one is Rescher (1984). The revised version is Rescher (1999b).
} 
science (cf. Rescher, 1998: pp. 165-169). This involves a specific framework for the problem of the limits of scientific prediction. On the other, he suggests a set of differences between prediction and explanation in science. In his judgment, these differences between them can be seen in four successive levels of philosophical analysis: logical, epistemological, methodological, and ontological (cf. Rescher, 1998: pp. 165-166).

1) From a logical point of view, prediction and explanation are-for Rescher-asymmetrical processes, because in explanatory arguments the conclusion is firmly supported by the premises, whereas the probability of a predictive statement coming true is always lower. 2) Epistemologically, explanation has a causal linkage of knowledge that is much clearer than in the case of prediction, where it is always possible to consider alternatives.

3) Methodologically, prediction and explanation are-for Rescher-also different, since we can explain processes that are really difficult to predict. 4) From an ontological viewpoint, there are a difference between explanation and prediction: the facts of the past are distinct from future developments, since they are still open. These differences have repercussions on the higher difficulty of prediction with respect to explanation. Thus, he insists that the predictive enterprise is a limited one, which is subject to epistemological and ontological obstacles (cf. Rescher, 2009c: ch. 6, pp. 91-122).

There are ontological limits that affect prediction, above all because prediction deals with not yet occurred phenomena that, consequently, are still open. This is highlighted by Rescher, who considers that "ontological limits exist insofar as the future of the domain at issue is developmentally open-causally undetermined or underdetermined by the existing realities of the present and open to the development of wholly unprecedent patterns owing to the contingencies of choice, chance, and chaos” (Rescher, 1998: p. 134).

Besides the ontological limits, there are epistemological obstacles to scientific prediction. They affect prediction "insofar as the future is cognitively inaccessible - either because we cannot secure the needed data, or because it is impossible for us to discover the operative laws, or even possibly because the requisite inferences and/or calculations involve complexities that outrun the reach of our capabilities” (Rescher, 1998: p. 134). Consequently, Rescher's analysis of the epistemological limits that affect predictability includes a bounded rationality approach (cf. Gonzalez, 2003).

Commonly, in Rescher's system of philosophy—a pragmatic idealism - the epistemological dimension has primacy over the ontological aspect (cf. Gonzalez, 1999). Our concepts and mental categories allow us to articulate the reality. Thus, science is our science: it is the product of an activity carried out by human agents with limited capabilities, and in an environment where, usually, the available information is also limited. In this regard, he accepts that "as Kant maintained, the limits of our experience set limits to our science" (Rescher, 1999b: p. 216).

Following this epistemological approach, Rescher considers that uncertainty is the main obstacle to scientific prediction in the epistemological level. His approach insists in this point: "the circumstances of our existence are such that many of our decisions - and many of the most important ones - have to be made under conditions of unavoidable uncertainty” (Rescher, 2003b: p. 33). This especially affects prediction, insofar as prediction is oriented to a possible future, and uncertainty can be a clear obstacle to predictability.

Uncertainty, understood as a characteristic limit to scientific prediction, can be seen according to several degrees: 1) uncertainty can involve unpredictability (that is, the impossibility to obtain a prediction); 2 ) it is possible that uncertainty entails not-predictability with regard to a concrete issue (the current impossibility to state a prediction $)^{5}$; and 3) uncertainty can make it difficult to achieve an ideal degree of accuracy and precision. In this case, it might only be possible to obtain a generic prediction, instead of a specific prediction ${ }^{6}$.

\section{Uncertainty as an Obstacle to Predictive Foreknowledge}

Regarding how to address the problem of predictive uncertainty, cognitive or epistemic rationality is the starting point. But Rescher does not endorse an approach to rationality based on the idea of maximization, as mainstream

\footnotetext{
${ }^{4}$ On the differences between explanation and predictions in Rescher’s account also, see also Rescher (1958); Rescher \& Helmer (1959); and Rescher (1970).

${ }^{5}$ This distinction between "not-predictability" and "unpredictability" is in Gonzalez (2010), p. 289. About this issue, it also can be seen Eagle (2005).

${ }^{6}$ Regarding what we can predict or not in science, Rescher thinks that the best source of information we have comes from science itself: it is not an external issue. Moreover, only science itself can inform us about the achievable degree of precision for scientific prediction. This depends on circumstances such as the scope — short, medium or long run - the available technology, etc. Additionally, it also depends on the question we want to ask. In principle, the more concrete the question is, the more complicated it will be to answer it accurately. Rescher, N., Personal communication, 17.6.2014.
} 
economists—-for example- does ${ }^{7}$. He considers that human rationality is, in fact, a bounded rationality ${ }^{8}$. In his judgment, rationality is bound to a circumstantial optimization (the best thing that can be done in a concrete situation), instead of being associated with something absolute or maximization (cf. Rescher, 1988; Rescher, 1987: pp. 55-84; especially, pp. 71-79). This has to do with the human beings environmental conditions or social milieu, which are usually affected by uncertainty.

Uncertainty is one of the aspects that goes hand in hand with bounded rationality. On the one hand, it is not usual that we have all the relevant information; and, on the other, human ability to compute information is also limited (cf. Rescher, 2003a, ch. 11: pp. 187-206). Hence, in Rescher's approach, rationality and uncertainty are closely related. This has direct repercussions on scientific prediction, insofar as it is the result of a rational activity. Moreover, this rational activity is oriented to a future that, in principle, has a number of possibilities.

\subsection{Rational Prediction as the Result of a Process}

In Rescher's conception, rational prediction is the result of a process. It involves several aspects: 1) prediction is obtained where there is the relevant information about past and present events; 2) the paths reflected in this body of data for prediction are discerned; and 3) the patterns detected in past and present phenomena are stable, to some extent, so they continue into the future (cf. Rescher, 1998: p. 86). If we consider these preconditions for rational prediction, it seems clear that uncertainty is, de facto, one of the main limits to predictability.

It should be emphasized that, according to Rescher, "uncertainty produced by sheer ignorance is clearly the most obvious obstacle to prediction" (Rescher, 1998: p. 135). Thus, although the phenomenon that we are trying to predict is - or may be-a regular one, the failure is still possible when all the relevant information about its operation is not available. Obtaining the relevant information is a necessary condition to predictability. However, too often it is difficult —or even impossible — for human beings to gain access to the information (at least, to the relevant information).

This aspect leads Rescher to accept that "the limits of one's information set unavoidable limits to one's predictive capacities” (Rescher, 1998: p. 135). Nevertheless, it is necessary to distinguish between uncertainty and ignorance. Ignorance means the complete lack of information about a concrete issue, whereas uncertainty has to do with the characteristic of indecisiveness. Thus, "with uncertainty we know (or think we know) what the range of possibilities is: it is based on (presumed) knowledge of the possibility range for correct. Accordingly we can generally grapple with uncertainty by means of probabilities-at least in favorable circumstances” (Rescher, 2009a: p. 57).

Even when it was possible to deal with uncertainty by means of probabilistic knowledge, this may not be good enough to guarantee a scientific prediction. Firstly, available information can be insufficient, making the predictive task difficult: "possibilities rest on actualities that require information to project possibilities, although unfortunately, misinformation will also come into play” (Rescher, 2009a: p. 58). Thus, uncertainty might affect the probabilistic calculus, because the available information might be insufficient or wrong.

Secondly, Rescher insists that prediction cannot be reduced to a probabilistic statement. In his judgment, to make a prediction is something more than assigned probability to phenomena's occurrence. In fact, he thinks that "the probability of a prediction thus affords an index of its acceptability-a measure of the extent to which rational confidence in its realization is warranted in the prevailing circumstances” (Rescher, 1998: p. 44). Consequently, claiming the occurrence of something (that is, making a prediction) is different from claiming that something is going to happen with certain probability. From this viewpoint, probability can be relevant to predict the degree of uncertainty of the obtained forecast.

Thirdly, since scientific prediction is the result of an intellectual rational activity, it should be made on the basis of available knowledge and the control of the variables that are relevant with respect to the phenomenon at issue. It also should be based on the appropriate inferences. This will lead to reduce the uncertainty associated with future phenomena, and to the conclusion of reliable and correct predictions. Thus, probability can be a tool that helps to overcome the obstacles related to uncertainty, but probabilistic knowledge - by itself alone-is not enough to obtain a prediction.

At the same time, the difficulty of achieving appropriate knowledge about the studied phenomena has repercussions on the temporal dimension, which affects the scope of prediction. Rescher distinguishes between long-run forecast and short-run forecast, depending on the temporal distance of the predicted phenomenon with

\footnotetext{
${ }^{7}$ About rationality as maximization and the alternative of bounded rationality, see Gonzalez (1997).

${ }^{8}$ The notion of "bounded rationality" has been developed by Herbert A. Simon. On this issue, see the papers compiled in Simon (1982a; 1982b; and 1997).
} 
respect to the present moment (cf. Rescher, 1998: pp. 76-78). Thus, to the extent we cannot predict what we cannot conceive (cf. Rescher, 2012), uncertainty will increase as we try to predict a more distant future (however, this is not a general rule: some phenomena can be easier to predict in the long run than in the short run) (cf. Rescher, 1998: pp. 77-78).

According to Rescher's viewpoint, predicting is similar to trying to see through the fog: "very little can be seen at a distance-and that little with but little clarity" (Rescher, 1998: p. 76). Undoubtedly, the problem of complexity can increase uncertainty. Even if it is known that something is possible, this sometimes might be insufficient to make a prediction. The more complex the studied phenomenon, the more problematic it will be, in principle, to obtain a reliable prediction about it.

There is also another aspect that adds difficulty to scientific prediction: uncertainty is related with predictive scatter. When we are dealing with a limited body of information, it is possible that various competing theories arise. This can lead to conflicting predictions. Hence, "the prospect of conflicting predictions has to be accepted as a pervasively recurrent phenomenon” (Rescher, 1998: p. 135). Conflicting predictions concern both the natural sciences and, to a greater extent, the social sciences.

\subsection{Uncertainty and the Future Science}

When the question at issue is the prediction about the development of future science, uncertainty is also present. In fact, Rescher maintains that future science is unpredictable. He thinks on the Kantian "principle of question proliferation" that intervenes here making the knowledge of future science impossible (at least, in a specific way). According to this principle, each answer given to solve a problem makes new questions arise, which, in turn, needs an answer (cf. Rescher, 1999a: pp. 120-121). Furthermore, we cannot predict what questions we will ask in the future, because we cannot anticipate what the answers to currently open questions will be. In this case, the available information about past developments does not justify an inference about the future advancements (cf. Rescher, 2012).

According to Rescher, scientific progress is basically of a conceptual nature. Thus, scientific research advances trough conceptual creativity. Consequently, "the questions we can pose are limited by our conceptual horizons” (Rescher, 1995: p.76). Following this way, prediction about the future science is only possible at a generic level. This is so because there is a cognitive indetermination here: the more detailed and precise the prediction is, the less confidence we can attribute to it. It is possible, for example, to predict with certainty that scientific means for observation and experimentation will improve in the future, but it is not possible to anticipate what these improvements will be.

This allows us to infer that uncertainty has more weigh in specific predictions than in generic predictions. This is so because there is a relation of balance between informativeness (exactness, detail, precision, etc.) and security, both in scientific knowledge, in general, and in scientific prediction, in particular. Thus, as the degree of detail of the prediction increases, the uncertainty with respect to its reliability also increases. This is an especially relevant question, since the utility of the prediction lies in its informativeness.

Rescher considers that "an ironic but critically important feature of scientific inquiry is that the unforeseeable tends to be of special significance just because of its unpredictability. The more important the innovation, the less predictable it is, because its very unpredictability is a key index of importance" (Rescher, 2009b: p. 15). This increases the problem of uncertainty because, generally, those things we do not know are, for that very reason, the most relevant for us.

On this basis, it is not advisable to obtain predictive security by losing informativeness, since the value of prediction lies in its content. Hence, it has to aspire to exactness and precision. However, when it is impossible to obtain a specific prediction due to uncertainty, at least a generic prediction could be possible. In this case, uncertainty does not entail unpredictability, but it acts as an obstacle with respect to the achievable degree of exactness and precision.

Comparatively, according to the type of phenomena that prediction is about, it is possible to claim—in my judgment-that prediction generates fewer difficulties in the natural sciences than in the social sciences. This is due to the higher level of complexity that social phenomena can have (cf. Gonzalez, 2011: pp. 319-330; especially, pp. 319-321), where uncertainty also has more weight than in natural phenomena ${ }^{9}$. Usually, Rescher's

\footnotetext{
${ }^{9}$ According to Rescher, social phenomena are more difficult to predict than natural phenomena. He considers that there is a very simple reason that explains this issue: social prediction deals, in principle, with people's acts and choices. How people consciously and deliberatively act depends not on the reality of the world, but on what people think about that reality (i.e., it depends on believes, ideas, expectations, etc. that are immensely variable). By contrast, natural prediction is about natural processes, which are an objective matter: they depend on the state of affairs of the world. Rescher, N., Personal communication, 10.6.2014.
} 
approach is focused on natural sciences (mainly, physics), so he leaves open the question of uncertainty with respect to social sciences (and, undoubtedly, he does not pay especial attention to prediction in the sciences of the artificial) ${ }^{10}$.

In principle, social sciences have to do with agents' actions and choices, which make their decisions in changeable social and historical settings. These structural and dynamic factors involve an additional source of complexity for prediction in these sciences. Too often, Rescher is focused on the problem of prediction with regard to the limits of the information, that is, on the internal aspects of science. In the specific case of scientific prediction, uncertainty has to do then with the future environment, so that available information does not allow us to predict or, at least, makes it difficult for those predictions to have the desired degree of exactness and precision.

It happens that in social sciences, in general, and in economics, in particular, there is an additional source of uncertainty. It is decision-making, which is related with the problem of rational decision. In economics, the problem of uncertainty is not only related with the future environment, but also has to be considered with regard to the agents' decision-making, that is usually carried through in circumstances of uncertainty ${ }^{11}$. Consequently, when prediction is about economic agents' decision-making, it is not usually to obtain a "foresight" (that is, the securest kind of prediction), but a mere "forecast," which always involves a margin of error and hence intrinsically involves uncertainty ${ }^{12}$.

In this context, it is possible to highlight the relevance of the methodological role of uncertainty, especially in the case of economic prediction (cf. Gonzalez, 2012: p. 91). When the result of economic forecasts "are known, the corresponding forecast errors and the anticipated forecast uncertainty can be used to evaluated the models from which the forecasts were generated” (Ericsson, 2002: p. 19). Thus, uncertainty has a methodological role that has repercussions on the use of the forecast as a test to assess the appropriateness of predictive models.

\section{Coda: Towards an Extension of the Analysis}

Considering all things, it is possible to state that, with regard to uncertainty, there are more questions than those contemplated by Rescher. In his approach, which is primarily oriented to the natural sciences, uncertainty is the main epistemological obstacle to predictability. It has to do with lack of knowledge about the regularities of phenomena, which is due to epistemic failures in obtaining or computing the information. But, besides the epistemological dimension, there are - in my judgment—a methodological aspect and an ontological feature, which can be seen clearly when the problem of prediction in economics is analyzed.

Methodologically, the problem arises about whether or not prediction is a necessary condition or test to have science. This is a question that has been argued above all in economics, where the problem of the lack of reliability of economic predictions has special relevance ${ }^{13}$. Uncertainty has influence on this question, so that it is possible to ask if it is good enough to obtain forecasts (predictions that involve uncertainty) instead of a genuine foresight.

This methodological problem related with prediction has ontological roots. De facto, in the social sciences and the sciences of the artificial, "it sits on the complexity of human activity involved in the social environment. This complexity contributes to the frequent lack of reliability of economic predictions, which has its roots in the object of study of this science: economic reality is a social and artificial undertaking (quehacer), which is commonly mutable, as a consequence of its dependence on the human activity that develops historically” (Gonzalez, 2012: p. 92). From this point of view, it is possible to consider uncertainty as a source of complexity in economic activity, so that it is an obstacle of special relevance to prediction in economics.

However, the epistemological dimension is fundamental, because uncertainty has to do, in principle, with the lack of knowledge about the regularities, which is due to the lack of information. For this reason, it is not usual that uncertainty involves "unpredictability", i.e., the actual impossibility of predicting. On the contrary, it can be possible to predict under conditions of uncertainty (at least, at the level of forecasts or generic predictions).

It must be considered that a phenomenon we cannot currently predict, because of the presence of uncertainty — or an issue that we can only predict generically, or by means of forecasts—can be predictable in the future.

\footnotetext{
${ }^{10}$ This expression is used following Simon (1996).

${ }^{11}$ About uncertainty as an obstacle to prediction in social sciences, in general, and in economic science, in particular, cf. Simon (2000).

${ }^{12}$ On the conceptual differences between "foresight” and “forecast," see Gonzalez (2010), pp. 261-263.

${ }^{13}$ About prediction as the "scientific test” of economics, see Gonzalez (2006), pp. 83-112. The approaches' of four Nobel Prize winners in economics are analyzed in this text: Milton Friedman, John Hicks, James Buchanan and Herbert Simon.
} 
Even more, the exactness and the degree of precision of the obtained predictions can increase. In this case, it is necessary to stress the rational basis of scientific prediction, since it is possible to overcome uncertainty if the knowledge and control of the relevant variables increase.

From an internal perspective about science, Rescher makes very interesting contributions in order to address the limits of science as "barriers" and, above all, as "confines". These reflections have an impact on prediction, both in its possibility as rational activity of scientific character, and about its scope in terms of precision and exactness. But his approach does not encompass the entire problem. As a matter of fact, the external dimension of science has very little presence in his analysis. In addition, his approach is too centered on natural science, so that it does not grasp all the complexity that affects social sciences and sciences of the artificial.

\section{Acknowledgements}

This research is supported by the Program FPU of the Spanish Ministry of Education, Culture and Sport. I am grateful to Wenceslao J. Gonzalez and Nicholas Rescher for their suggestions and comments regarding this paper.

\section{References}

Eagle, A. (2005). Randomness Is Unpredictability. British Journal for the Philosophy of Science, 56, 749-790. http://dx.doi.org/10.1093/bjps/axi138

Ericsson, N. R. (2002). Predictable Uncertainty in Economic Forecasting. In M. Clements, \& D. F. Hendry (Eds.), A Companion to Economic Forecasting (pp. 19-44). Oxford: Blackwell.

Gonzalez, W. J. (1997). Rationality in Economics and Scientific Predictions: A Critical Reconstruction of Bounded Rationality and its Role in Economic Predictions. Poznan Studies in the Philosophy of the Sciences and the Humanities, 61, 205-232.

Gonzalez, W. J. (1999). Racionalidad científica y actividad humana: Ciencia y valores en la Filosofía de Nicholas Rescher. In N.Rescher (Ed.), Razón y valores en la Era científico-tecnológica (pp. 11-44). Barcelona: Paidós.

Gonzalez, W. J. (2003). Racionalidad y Economía: De la racionalidad de la Economía como Ciencia a la racionalidad de los agentes económicos. In W. J. Gonzalez, (Ed.), Racionalidad, historicidad y predicción en Herbert A. Simon (pp. 65-96). A Coruña: Netbiblo.

Gonzalez, W. J. (2006). Prediction as Scientific Test of Economics. In W. J. Gonzalez \& J. Alcolea (Eds.), Contemporary Perspectives in Philosophy and Methodology of Science (pp. 83-112). A Coruña: Netbiblo.

Gonzalez, W. J. (2008). Rationality and Prediction in the Sciences of the Artificial: Economics as a Design Science. In M. C. Galavotti, R. Scazzieri \& P. Suppes (Eds.), Reasoning, Rationality, and Probability (pp. 165-186). Stanford: CSLI Publications.

Gonzalez, W. J. (2010). La predicción científica. Concepciones filosófico-metodológicas desde H. Reichenbach a N. Rescher. Barcelona: Montesinos.

Gonzalez, W. J. (2011). Complexity in Economics and Prediction: The Role of Parsimonious Factors. In D. Dieks, W. J. Gonzalez, S. Hartman, Th. Uebel, \& M. Weber (Eds.), Explanation, Prediction, and Confirmation (pp. 319-330). Dordrecht: Springer. http://dx.doi.org/10.1007/978-94-007-1180-8 22

Gonzalez, W. J. (2012). La vertiente dinámica de las Ciencias de la Complejidad. Repercusión de la historicidad para la predicción científica en las Ciencias Diseño. In W. J. Gonzalez (Ed.), Las Ciencias de la Complejidad: Vertiente dinámica de las Ciencias de Diseño y sobriedad de factores (pp. 73-106). A Coruña: Netbiblo.

Radnitzky, G. (1978). The Boundaries of Science and Technology. In The Search for Absolute Values in a Changing World. Proceedings of the 6th International Conference on the Unity of Sciences (Vol. 2, pp. 1007-1036). New York: International Cultural Foundation Press.

Rescher, N. (1958). On Prediction and Explanation. British Journal for the Philosophy of Science, 8, 281-290. http://dx.doi.org/10.1093/bjps/VIII.32.281

Rescher, N., \& Helmer, O. (1959). On the Epistemology of the Inexact Sciences. Management Science, 6, 25-52. http://dx.doi.org/10.1287/mnsc.6.1.25

Rescher, N. (1970). Scientific Explanation. New York: The Free Press.

Rescher, N. (1984). The Limits of Science. Berkeley and Los Angeles: University of California Press.

Rescher, N. (1987). Maximization, Optimization, and Rationality. On Reasons Why Rationality Is Not Necessarily a Matter of Maximization. In N. Rescher, Ethical Idealism. An Inquiry into the Nature and Function of Ideals (pp. 55-84). Berkeley 
and Los Angeles: University of California Press.

Rescher, N. (1988). Rationality: A Philosophical Inquiry into the Nature and the Rationale of Reason. Oxford: Clarendon Press.

Rescher, N. (1990). Our Science as O-U-R Science. In N. Rescher, A Useful Inheritance. Evolutionary Aspects of the Theory of Knowledge (pp. 77-104). Savage: Rowman and Littlefield.

Rescher, N. (1992). A System of Pragmatic Idealism. Vol. I: Human Knowledge in Idealistic Perspective. Princeton, NJ: Princeton University Press.

Rescher, N. (1993). A System of Pragmatic Idealism. Vol. II: The Validity of Values: Human Values in Pragmatic Perspective. Princeton, NJ: Princeton University Press.

Rescher, N. (1994). A System of Pragmatic Idealism. Vol. III: Metaphilosophical Inquires. Princeton, NJ: Princeton University Press.

Rescher, N. (1995). Satisfying Reason. Studies in the Theory of Knowledge. Dordrecht: Kluwer. http://dx.doi.org/10.1007/978-94-011-0483-8

Rescher, N. (1998). Predicting the Future: An Introduction to Theory of Forecasting. Albany, NY: Sate University of New York Press.

Rescher, N. (1999a). Razón y valores en la Era científico-tecnológica. Barcelona: Paidós.

Rescher, N. (1999b). The Limits of Science (revised ed.). Pittsburgh, PA: University of Pittsburgh Press.

Rescher, N. (2003a). Epistemology: An Introduction to the Theory of Knowledge. Albany, NY: State University of New York Press.

Rescher, N. (2003b). Deliberative Conservatism. In N. Rescher, Sensible Decisions. Issues of Rational Decision in Personal Choice and Public Policy (pp. 33-38). Lanham, MD: Rowman and Littlefield.

Rescher, N. (2009a). Cognitive Compromise. On Managing Cognitive Risk in the Face of the Imperfect/Flawed. In N. Rescher, Epistemological Studies (pp. 57-63). Heusenstamm: Ontos Verlag.

Rescher, N. (2009b). Unknowability: An Inquiry into the Limits of Knowledge. Lanham, MD: Lexington Books.

Rescher, N. (2009c). Ignorance: On the Wider Implications of Deficient Knowledge. Pittsburgh, PA: University of Pittsburgh Press.

Rescher, N. (2012). The Problem of Future Knowledge. Mind and Society, 11, 149-163. http://dx.doi.org/10.1007/s11299-012-0099-8

Simon, H. A. (1982a). Models of Bounded Rationality. Vol. 1: Economic Analysis and Public Policy. Cambridge, MA: The MIT Press.

Simon, H. A. (1982b). Models of Bounded Rationality. Vol. 2: Behavioral Economics and Business Organization. Cambridge, MA: The MIT Press.

Simon, H. A. (1996). The Sciences of the Artificial (3rd ed.). Cambridge, MA: The MIT Press.

Simon, H. A. (1997). Models of Bounded Rationality. Vol. 3: Empirically Grounded Economic Reason. Cambridge, MA: The MIT Press.

Simon, H. A. (2000). Bounded Rationality in Social Science: Today and Tomorrow. Mind and Society, 1, 25-39. http://dx.doi.org/10.1007/BF02512227 
Scientific Research Publishing (SCIRP) is one of the largest Open Access journal publishers. It is currently publishing more than 200 open access, online, peer-reviewed journals covering a wide range of academic disciplines. SCIRP serves the worldwide academic communities and contributes to the progress and application of science with its publication.

Other selected journals from SCIRP are listed as below. Submit your manuscript to us via either submit@scirp.org or Online Submission Portal.
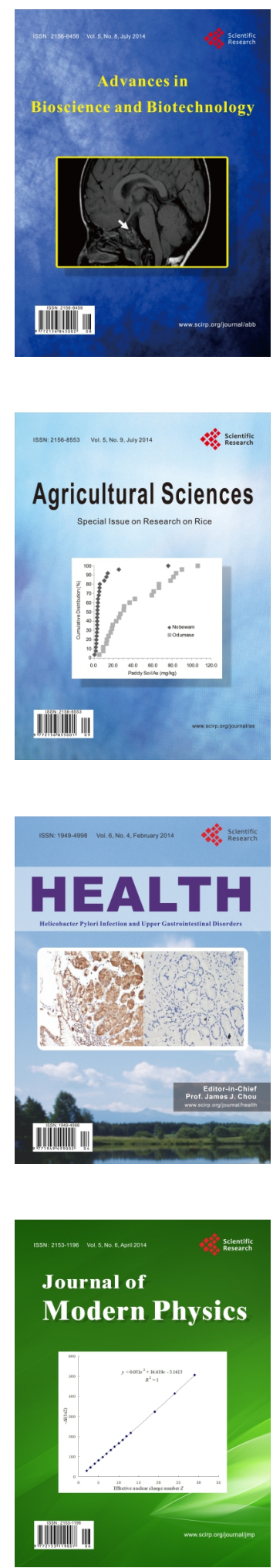
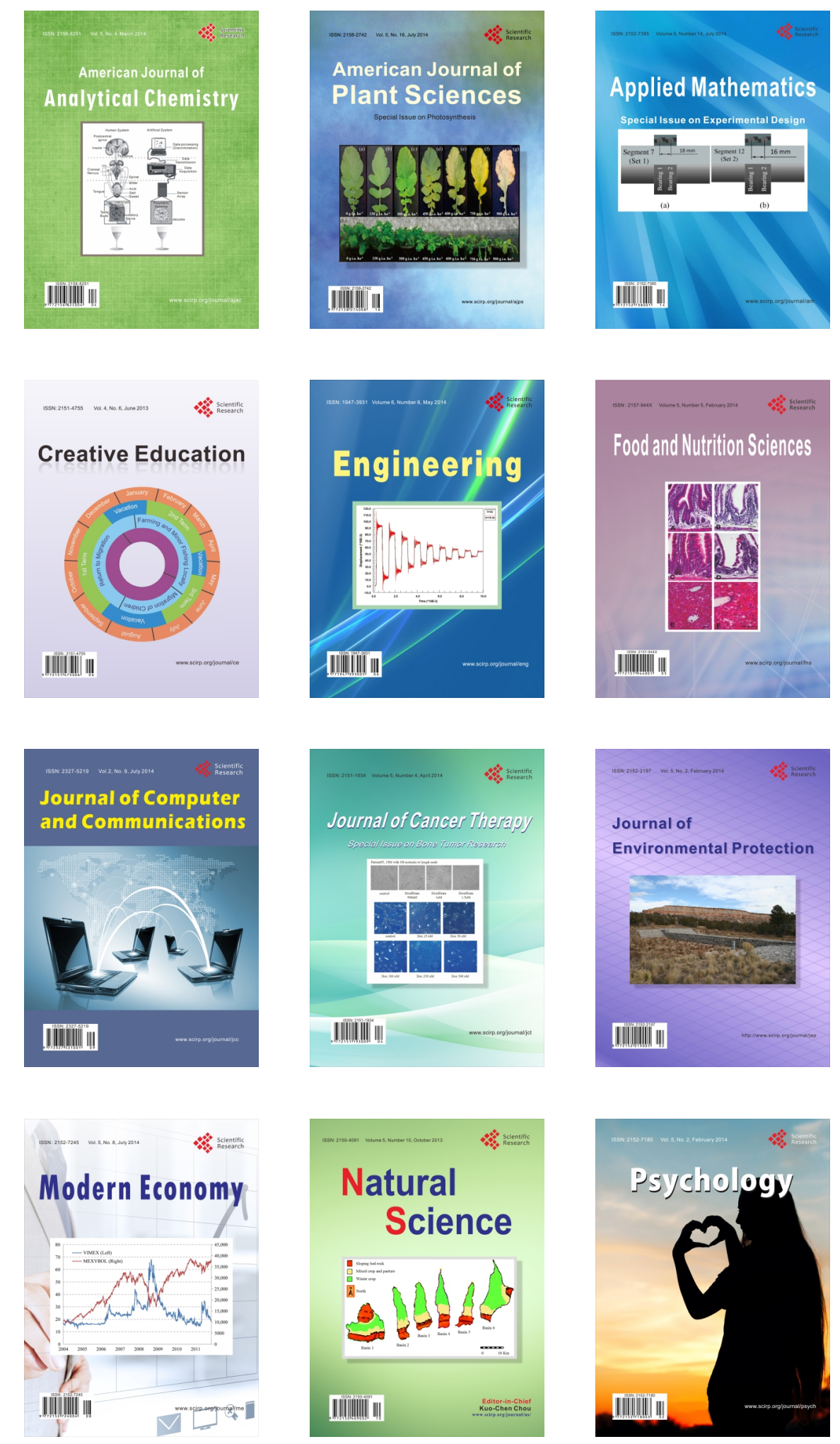